Revista Tecnologia e Ambiente, v. 28, 2022, Criciúma, Santa Catarina/SC - ISSN

Eletrônico 2358-9426 e ISSN Impresso 1413-8131

\title{
DISTRIBUIÇÃO DE FOCOS DE CALOR NA BACIA HIDROGRÁFICA DO RIO COXIPÓ, NO MUNICÍPIO DE CUIABÁ (MATO GROSSO)
}

\author{
DISTRIBUTION OF HEAT SOURCES IN THE COXIPÓ \\ WATERSHED IN THE IN THE MUNICIPALITY OF CUIABÁ \\ (MATO GROSSO)
}

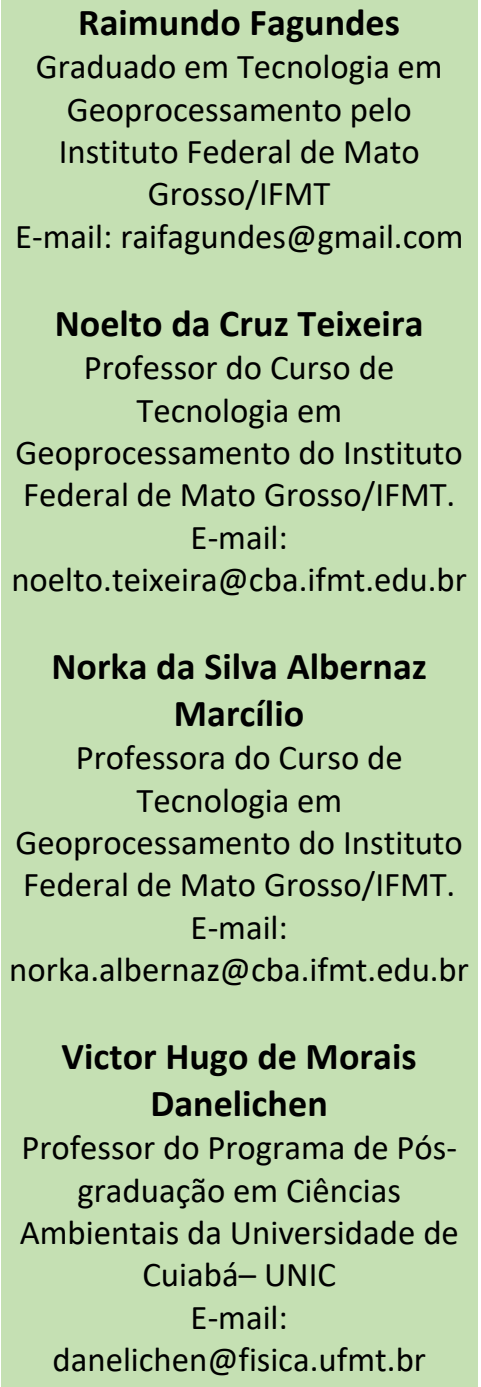

\section{RESUMO}

A bacia hidrográfica é considerada um sistema estruturado e adaptado às condições externas como unidade territorial destinada a pesquisa, planejamento e gestão ambiental. Com a ocupação acelerada do espaço geográfico pelo homem, a vegetação sofreu transformações e tornou-se susceptível a ameaças por focos de calor. Neste contexto, o presente trabalho teve como objetivo identificar e analisar a distribuição geográfica dos focos de calor na Bacia Hidrográfica do Rio Coxipó (BHRC) no período seco dos anos de 2015, 2017 e 2019, utilizando geotecnologias. Os resultados mostraram uma tendência na distribuição geoespacial de ocorrência de focos de calor para toda bacia com maior incidência na classe Formação Savânica $(57,55 \%)$, seguida da classe Pastagem $(30,52 \%)$ e Formação Florestal $(10,66 \%)$. Nas margens de rodovias e limites urbanos foram registrados um percentual de $21,40 \%$. Conclui-se que a ocorrência de focos de calor na estação seca manteve uma relação inversa com a precipitação pluviométrica e o uso e cobertura da terra influenciou na distribuição dos focos de calor.

Palavras-Chaves: Geotecnologias, Padrão espacial, SIG.

\section{ABSTRACT}

The hydrographic basin is considered a structured system adapted to external conditions as a territorial unit destined for research, planning and environmental management. With the accelerated occupation of geographic space by man, the vegetation underwent transformations and became susceptible to threats from hot spots. In this context, this study aimed to identify and analyze the geographic distribution of heat sources in the Coxipó River Basin (BHRC) in the dry period of 2015, 2017 and 2019, using geotechnologies. The results showed a trend in the geospatial distribution of hotspots for the entire basin, with the highest incidence in the Savânica Formation $(57,55 \%)$ class, followed by the Pasture $(30,52 \%)$ and Forestry $(10,66 \%)$ classes. On the margins of highways and urban limits, a percentage of $21,40 \%$ was registered. It is concluded that the occurrence of hot spots in the dry season had an inverse relationship with rainfall and land use and land cover influenced the distribution of hot spots.

Keywords: Geotechnologies, Spatial Pattern, GIS. 
Revista Tecnologia e Ambiente, v. 28, 2022, Criciúma, Santa Catarina/SC - ISSN Eletrônico 2358-9426 e ISSN Impresso 1413-8131

\section{INTRODUÇÃO}

Considerando que as feições naturais se configuram como sistemas estruturados, dependentes e adaptados às condições externas, nos estudos direcionados a pesquisa, planejamento e gestão ambiental, tem-se adotado, amplamente, a bacia hidrográfica como unidade territorial (LIMA, 2020).

A BHRC está inserida no bioma Cerrado e considerado o segundo maior bioma brasileiro e Sul americano (TEIXEIRA, 2020). A contar com uma grande biodiversidade de espécies vegetais e animais, apresenta uma vegetação heterogênea, diversos tipos de solos, climas e fauna (STRASSBURG et al., 2017).

Apesar deste potencial biológico, os autores supracitados afirmaram que o Cerrado enfrenta ameaças devido à conversão da vegetação em parcelas destinada a agricultura e pastagens.

A ocorrência e a utilização do fogo datam de milhares de anos e sempre estiveram presentes para todos os que convivem na região do Cerrado (SOUZA, 2017). Esta tradição é utilizada na eliminação da cobertura vegetal das áreas para o cultivo agrícola, bem como, em áreas urbanas, onde a queima do lixo doméstico possui facilidade de combustão. Na década de 70 do século passado o processo de eliminação da cobertura vegetal foi implementado pelos incentivos governamentais com a exploração agropecuária de larga escala, visando a ocupação de terras e geração de lucros na região central e norte do Brasil.

Segundo White e White (2015), a vegetação do Cerrado possui dependência com as queimadas. $\mathrm{O}$ fogo apresenta, todavia, alguns aspectos positivos aos ecossistemas do Cerrado como a rebrota de algumas espécies para servir de alimentos aos animais silvestres, a quebra da dormência das sementes (LEMES et al., 2014) e os mecanismos reprodutivos para a indução da floração (RIBEIRO; FIGUEIRA, 2011).

No entanto, o descontrole do fogo pode transformar em incêndios intensos à medida que o material acumulado for submetido a intervalos maiores de queima, podendo ser altamente destrutivo como a supressão da vegetação e perdas de vidas silvestres e humanas Pode, também, causar impactos ambientais decorrente das emissões e incorporações dos principais gases nocivos na atmosfera como o dióxido de carbono $\left(\mathrm{NO}_{2}\right)$, monóxido de carbono $(\mathrm{CO})$, óxidos nitrosos $\left(\mathrm{NO}_{3}\right)$, hidrocarbonetos e partículas de aerossóis (PEREIRA et al., 2016), trazendo prejuízos relevantes à saúde humana, 
Revista Tecnologia e Ambiente, v. 28, 2022, Criciúma, Santa Catarina/SC - ISSN Eletrônico 2358-9426 e ISSN Impresso 1413-8131

principalmente em aglomerados urbanos com a presença de doenças respiratórias e intoxicações adquiridas.

O material combustível e o seu arranjo constituem um fator decisivo na propagação do fogo, importante para estabelecer o quanto se torna fácil ou difícil do fogo se propagar, considerando os aspectos de continuidade referente à disposição horizontal, densidade e a forma com que os estratos da vegetação são espacialmente distribuídos, além da sua quantificação em termos de matéria seca que define a intensidade de calor liberado pelo fogo e a determinação do nível de propagação (SOARES; BATISTA; TETTO, 2017).

Além das características dadas pelos materiais combustíveis ao comportamento do fogo, de acordo com Oliveira, White e Ribeiro (2018), as variáveis climáticas como a temperatura do ar, velocidade do vento e a precipitação pluviométrica reúnem os principais fatores determinantes para a ocorrência e propagação da queima da vegetação. Neste sentido, tais variáveis influenciam na quantidade de água presente no material combustível em relação ao peso do material seco e na biomassa vegetal em processo de ignição, possuindo o material maior dificuldade de se queimar quanto maior for a sua umidade. Neste contexto, a BHRC nos meses secos de maio a setembro experimenta um período de estiagem, conferindo características ideais de propagação do fogo à vegetação e a ocorrência de focos de calor.

O Instituto Nacional de Pesquisas Espaciais (INPE) nas últimas décadas vem contribuindo com um sistema de detecção de queimadas em todo o Brasil a partir de diversos sensores a bordo de satélites artificiais polares e geoestacionários. Segundo os dados, o Estado de Mato Grosso tem-se destacado com maiores números de focos de calor nos anos de 2013 e 2019 em relação aos demais Estados do Brasil.

O conhecimento destes focos de calor é fundamental para iniciativas governamentais de prevenção de queimadas e incêndios (mais danosos ao ecossistema) na vegetação. Eles são detectados e monitorados, atualmente, por sensores orbitais que operam na faixa do infravermelho termal, aproximadamente 10,4 a 12,5 $\mu \mathrm{m}$ (SILVA, COSTA; MATRICARDI, 2017) e são provenientes de imagens de satélites de baixa resolução espacial e alta resolução temporal, disponível, gratuitamente, pelo INPE (INPE, 2019). 
Nesta perspectiva, as geotecnologias como técnicas de coleta, processamento, análise e disponibilidade de informação georreferenciada, com soluções de hardware, software e profissionais especializados tem sido responsável por uma expressiva revolução e contribuição nos estudos geoambientais, propiciando avanços na obtenção de dados, tratamento e geração de informações relacionadas ao uso e cobertura da Terra (COELHO; GIMENES; GOULART, 2020).

Em adição, as ferramentas de Sistemas de Informações Geográficas (SIGs) são alternativas geotecnológicas de baixo custo, precisas e eficientes com possibilidades de geração de mapas temáticos e distribuição espaço-temporal de focos de calor em diferentes escalas.

Diversos trabalhos relacionados a ocorrência e a distribuição espaço-temporal de focos de calor em bacias hidrográficas no Brasil, utilizando geotecnologias foram feitos por pesquisadores (PEREIRA; SZLAFSZTEIN; ARAÚJO, 2016; OLIVEIRA; OLIVEIRA, 2017; ALBUQUERQUE, 2017; MENESES et al., 2019; SILVA et al., 2020). Oliveira e Oliveira (2017) observaram que na porção do alto e médio curso do rio Acaraú-CE, nos anos de 2010 a 2015 a concentração dos focos de calor foi explicada por uma maior propensão dessas áreas ao plantio e à criação de gado. Meneses et al. (2019) avaliaram o uso de geotecnologias em uma sub-bacia do semiárido mineiro nos anos de 2005, 2010, 2015 e 2017 o que lhes permitiu inferências sobre a distribuição dos registros de focos com a indicação das áreas com predisposição a ocorrência de incêndios florestais.

Diante disso, o conhecimento da distribuição espacial e quantificação dos focos de calor faz-se necessário para a compreensão da ocorrência dos incêndios florestais, importante para viabilizar ações de gestão para proteção ambiental. Assim, objetivou-se com este trabalho identificar e analisar a distribuição geográfica dos focos de calor na BHRC a dinâmica espaço-temporal, considerando a ocorrência de precipitações, cobertura vegetal e vias públicas.

\section{MATERIAIS E MÉTODOS}

\section{1. Área de estudo}

A área de estudo encontra-se na BHRC e possui $673,985 \mathrm{Km}^{2}$ inserida na região de Cerrado do Estado de Mato Grosso - MT nos municípios de Cuiabá e Chapada dos 
Revista Tecnologia e Ambiente, v. 28, 2022, Criciúma, Santa Catarina/SC - ISSN Eletrônico 2358-9426 e ISSN Impresso 1413-8131

Guimarães. Os seus contribuintes nascem nas partes mais elevadas do Parque Nacional da Chapada dos Guimarães com altitudes aproximadas de 800 m e deságuam no exutório no Rio Cuiabá. Os limites encontram-se entre as coordenadas geográficas de Latitude

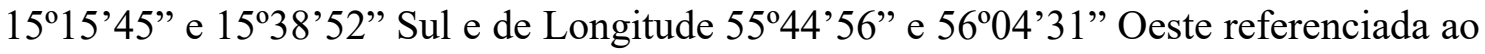
Datum Global WGS 84, conforme a Figura 1.

Figura 1 - Localização da Bacia Hidrográfica do Rio Coxipó, inserida nos municípios de Cuiabá e Chapada dos Guimarães - MT.
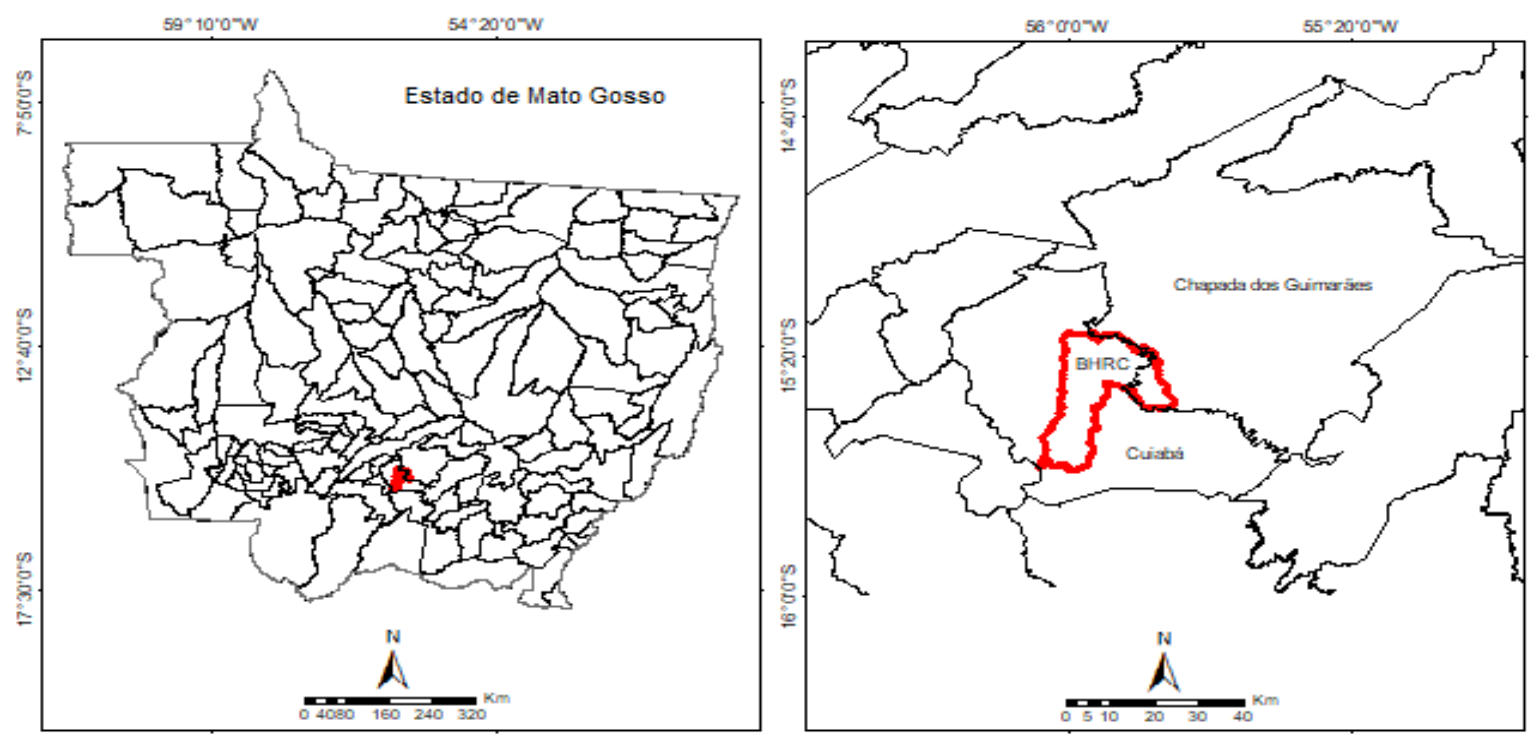

Fonte: Adaptado pelos Autores (2021)

O clima da região é semiúmido e de acordo com a classificado de Köppen se enquadra como Aw com período seco nos meses de maio a setembro, apresentando, conforme Instituto Nacional de Meteorologia - INMET (2018), precipitação média de $1372 \mathrm{~mm}$ por ano e temperatura do ar média anual de $26,9{ }^{\circ} \mathrm{C}$.

\subsection{Dados de Entrada e Processamento}

Para a delimitação dos limites da BHRC foi utilizado o MDE (Modelo Digital de Elevação) contido na imagem altimétrica SRTM (Shuttle Radar Topography Mission) com resolução espacial de um arco de segundo (30 x 30) compatível com a escala de 1:250000 das cartas topográficas sistematizadas pelo IBGE, obtidas no site da USGS. 
Os dados referentes as classes temáticas de cobertura vegetal foram adquiridas na plataforma do MapBiomas. Os shapefiles dos limites de municípios e de vias urbanas e rurais de Cuiabá e Chapada dos Guimarães foram baixados da página do IBGE.

Os focos de calor estudados na BHRC foram obtidos para os anos de 2015, 2017 e 2019 por meio do portal do INPE que disponibiliza feições pontuais no formato vetorial de focos de calor e de incêndios florestais coletados por satélites de referência em diferentes resoluções espaciais, radiométricas e temporais e detectam frente de fogo com no mínimo de $30 \mathrm{~m}$ de extensão por $1 \mathrm{~m}$ de largura que poderá ser utilizado em análises espaço-temporal de interesse local e regional.

Os dados meteorológicos diários e mensais de precipitação, utilizados foram adquiridos do INMET. Os dados foram processados no ambiente computacional SIG com o uso do software ArcGis 10.3 e o excel 2016 na tabulação dos dados e geração de gráficos.

\subsection{Metodologia Aplicada}

A metodologia utilizada delineou-se conforme o fluxograma da Figura 2. A delimitação automática foi realizada conforme Medeiros, Ferreira e Ferreira (2009).

Figura 2 - Fluxograma Metodológico para os anos de 2015, 2017 e 2019 da BHRC.

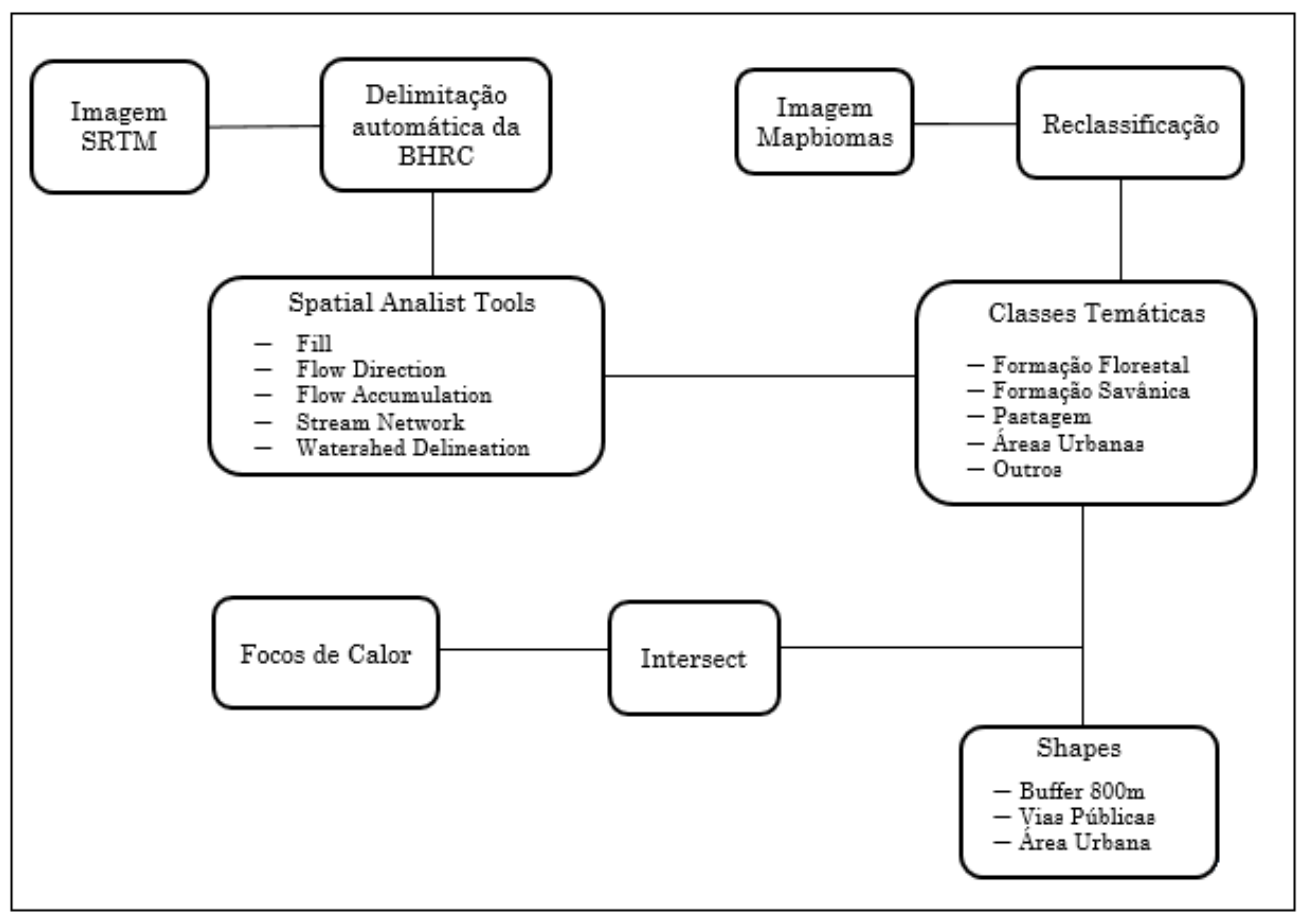

Fonte: Autores (2021). 
Revista Tecnologia e Ambiente, v. 28, 2022, Criciúma, Santa Catarina/SC - ISSN Eletrônico 2358-9426 e ISSN Impresso 1413-8131

Assim, a partir do MDE da imagem SRTM, utilizando o programa ArcGis, versão 10.3, por meio da extensão Spatial Analist Tools (hidrology) foram realizadas as seguintes etapas: (a) Eliminação de dados nulos, (b) Reentrâncias e saliências do modelo (Fill Sinks), (c) Geração das direções de fluxos (Flow Direction), (d) Fluxo acumulado (Flow Accumulation) rede de drenagem (Stream Networks) e, (f) Delimitação da bacia hidrográfica propriamente dita (Watershed Delineation). Outros pesquisadores fizeram trabalhos similares, utilizando o mesmo processo automático de delimitação de bacias (COSTA; SOUZA; SILVA, 2016; SILVA et al., 2020; SANTANA; BLANCO; PESSOA, 2020).

A distribuição dos focos de calor na BHRC foi analisada, considerando as principais classes de cobertura vegetal da região como Formação Florestal, Formação Savânica e Pastagem, bem como Áreas Urbanas e Outros, a fim de atingir os objetivos deste estudo. Estas classes no formato raster foram reclassificadas com o uso da ferramenta Reclass a partir do total de classes pertencentes ao mapa original de vegetação do MapBiomas e, posteriormente, convertidas em shapefiles com as tabelas de atributos associadas.

Para quantificar os focos de calor em cada classe referente a estação seca dos anos de 2015, 2017 e 2019, utilizaram-se intersecções a partir da ferramenta Intersect entre os shapefiles das classes e os focos de calor ocorrido na região. Logo após, foi calculado a porcentagem de focos de calor que ocorreram em cada uma dessas classes.

Devido ao alto risco de ocorrência de focos de calor, a facilidade de ignição e a propagação do fogo próximos as estradas e rodovias em decorrência de atividades antrópicas foram criadas para este estudo faixas de deslocamentos de 800 metros paralelas às duas margens das vias existentes no interior da bacia com o uso da ferramenta Buffer com o objetivo de analisar a influência destas vias na porcentagem de focos de calor existentes na BHRC, como demonstrado nos trabalhos de Abreu e Souza (2016), Gomes, Sakamoto e Silva (2020) e Oliveira et al., (2020)

Os dados de precipitação durante a estação seca no período de estudo foram organizados em planilhas Excel e gerados gráficos a partir dos dados meteorológicos do INMET. Constituíram uma informação importante para a compreensão da umidade natural dos materiais combustíveis, responsáveis pela propagação dos incêndios florestais. 
Revista Tecnologia e Ambiente, v. 28, 2022, Criciúma, Santa Catarina/SC - ISSN Eletrônico 2358-9426 e ISSN Impresso 1413-8131

\section{RESULTADOS E DISCUSSÃO}

Ao analisar os resultados obtidos através do processamento e interpretação dos dados para o período estudado, constatou-se um total de 3.152 eventos de focos de calor para os meses secos do ano, sendo distribuídos em quantidades equivalentes a 773, $721 \mathrm{e}$ 1658 nos anos de 2015, 2017 e 2019, respectivamente, como mostra a Figura 3.

Figura 3 - Dados de focos de calor e precipitação pluviométrica da BHRC dos anos de 2015, 2017 e 2019.

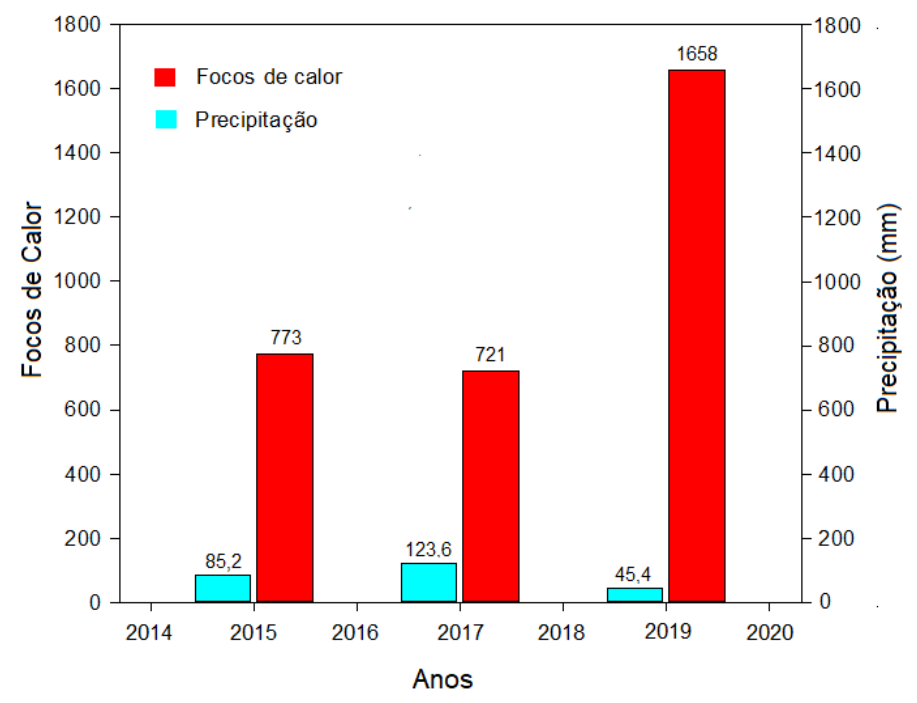

Fonte: Autores (2021)

A precipitação pluviométrica acumulada oscilou entre 45,4 mm no ano de 2019 a 123,6 mm em 2017. A quantidade de chuva acumulada nos meses secos do ano é um dos fatores que determina a disponibilidade de água no solo e o estado da vegetação (PRADO; COELHO, 2017), podendo impactar na ocorrência de focos de calor. Verifica-se na Figura 3 que o ano de 2019 apresentou a maior quantidade de focos (1658) e a menor precipitação pluviométrica $(45,4 \mathrm{~mm})$, computando variações de ocorrência de focos de 29,73\% em relação a 2017 que alcançou o menor índice de focos da série (721) e 28,08\% em relação ao ano de 2015 de valores intermediários para a precipitação $(85,2 \mathrm{~mm})$ e números de focos de calor (723), revelando a influência da chuva na ocorrência destes eventos na BHRC.

Estudos recentes por meio de geotecnologias mostram a influência sazonal na ocorrência de focos de calor nos biomas brasileiros. Leão, Ferreira e Strauch (2020), analisando a incidência de focos de calor no bioma Cerrado e Amazônico no Estado de Mato Grosso demonstraram que no período seco de 2016 houve mais eventos do que nos 
Revista Tecnologia e Ambiente, v. 28, 2022, Criciúma, Santa Catarina/SC - ISSN Eletrônico 2358-9426 e ISSN Impresso 1413-8131

demais meses do ano. Matos, Matricardi e Leal (2018) verificaram para o bioma Pantanal no município de Cáceres nos meses secos elevada incidência de queimadas atribuídos aos fatores climáticos onde foram identificadas as maiores temperaturas e baixos índices de precipitação. Além de outros como Jesus et al. (2020), Mazziero et al. (2019), Botelho et al. (2020), Ribeiro et al. (2020) e Sales et al. (2019).

A Figura 4 mostra a distribuição espacial dos focos de calor no interior da BHRC para o ano de 2015.

Figura 4 - Distribuição de focos de calor na BHRC do ano de 2015

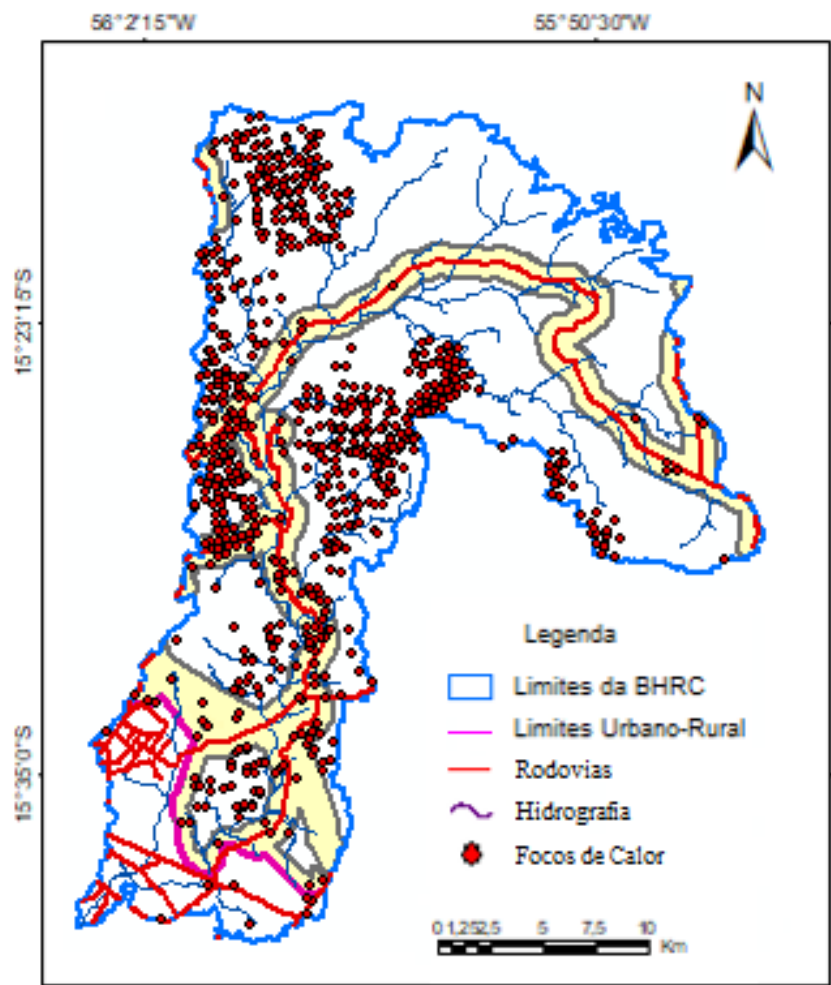

Fonte: Autores (2021)

Verifica-se que os focos de calor para o ano de 2015 foram mais concentrados na região centro-norte e sudeste da bacia. Parte da região norte e nordeste localizada na Unidade de Conservação de Chapada dos Guimarães, no Planalto dos Guimarães, onde se encontram as principais nascentes cuja vegetação é mais densa e altitudes mais elevadas, apresentando baixa densidade, assim como na área urbana da cidade de Cuiabá situada ao sul da BHRC.

A distribuição espacial dos focos de calor no ano de 2017, apresenta-se mais concentrada na região central da BHRC, conforme Figura 5. 
Revista Tecnologia e Ambiente, v. 28, 2022, Criciúma, Santa Catarina/SC - ISSN Eletrônico 2358-9426 e ISSN Impresso 1413-8131

Figura 5 - Distribuição de focos de calor na BHRC do ano de 2017

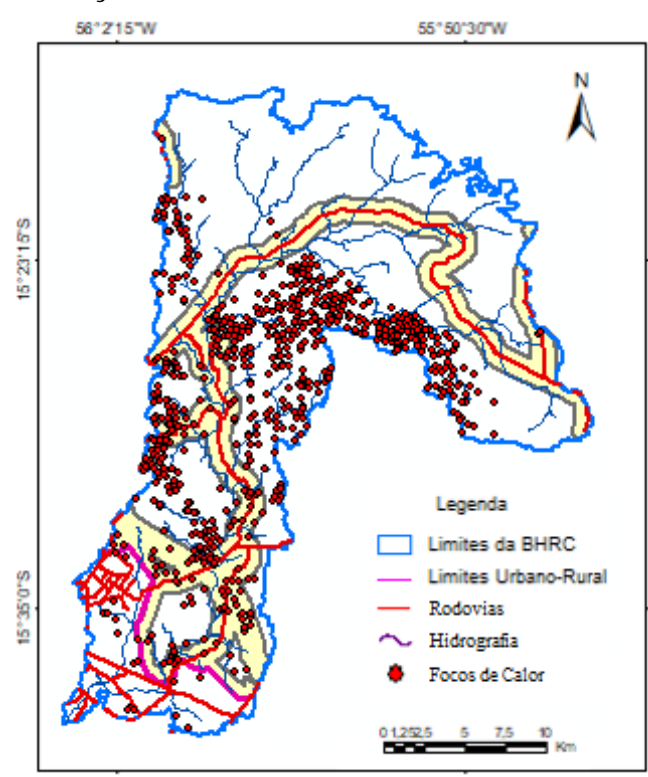

Fonte: Autores (2021)

Nota-se menor concentração na região norte e nordeste, um acréscimo na densidade na porção mais ao sul e uma baixa densidade para a área urbana de Cuiabá comparada com o ano de 2015.

Para o último ano da série temporal estudada, 2019, que apresentou a maior incidência de focos de calor, houve uma elevada concentração na região central e porção nordeste da BHRC. Como mostra a Figura 6 na região extremo norte e nordeste permaneceram com baixas densidades, também, para este ano, mas com maior ocorrência comparada com os anos de 2015 e 2017.

Figura 6 - Distribuição de focos de calor na BHRC do ano de 2019

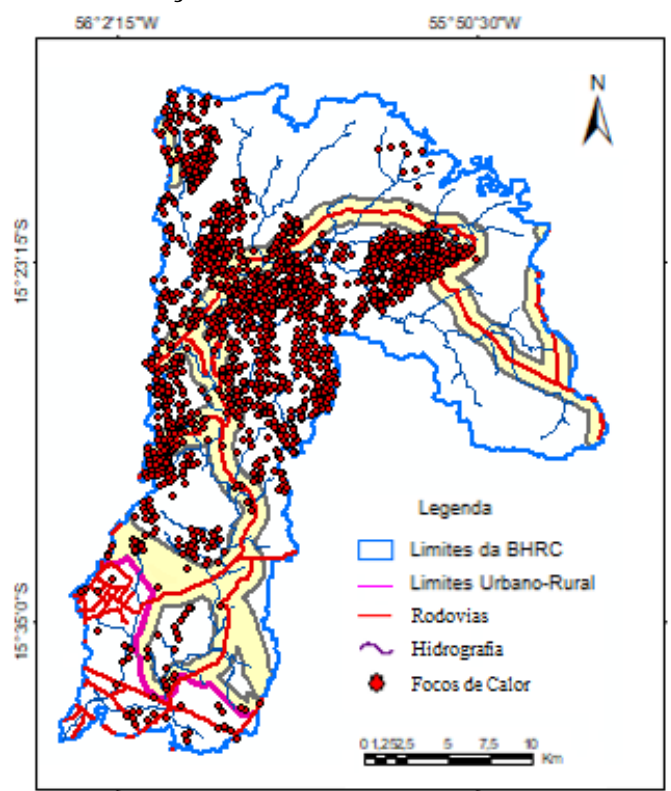

Fonte: Autores (2021) 
Conforme exposto nas figuras anteriores foi possível verificar uma tendência espacial de ocorrência de focos de calor para toda bacia, evidenciando, também, concentrações próxima ao limite urbano-rural para todos anos o que torna referência para ações públicas no combate e prevenção ao fogo.

Apesar do número de anos adotado para este trabalho as quantidades de focos de calor, distribuíram-se de forma semelhante.

Uma alternativa mais adequada na avaliação deste padrão poderia ser o uso de uma série com maior espaço de tempo e a adoção de outras variáveis climáticas como vento, umidade relativa do ar, bem como a topografia do terreno.

Para melhor compreender a distribuição dos focos de calor na BHRC foi analisado o uso e cobertura da Terra e as áreas às margens das vias públicas e urbanas como mostra a Figura 7. Os resultados demonstraram que as maiores ocorrências foram registradas nas classes de vegetação típica de Cerrado (Formação Savânica) e Pastagem e menores em classes de Floresta e Área Urbana, conforme Tabela 1.

Tabela 1 - Uso do solo e distribuição de focos de calor

\begin{tabular}{ccccccr}
\hline Ano & $\begin{array}{c}\text { Formacão } \\
\text { Florestal }\end{array}$ & $\begin{array}{c}\text { Formação } \\
\text { Savânica }\end{array}$ & Pastagem & $\begin{array}{c}\text { Área } \\
\text { Urbana }\end{array}$ & Outros & Total \\
\hline 2015 & 76 & 427 & 259 & 04 & 07 & 773 \\
2017 & 109 & 376 & 229 & 03 & 04 & 721 \\
2019 & 151 & 1011 & 474 & 11 & 11 & 1658 \\
\hline Total & 336 & 1814 & 962 & 18 & 22 & 3152 \\
\hline
\end{tabular}

Fonte: Autores (2021)

A Tabela 1 mostra as quantidades parciais e totais dos focos de calor em cada classe, destacando a classe de Formação Savânica com um registro total de 1814 focos de calor e um percentual de $57,55 \%$.

Resende, Cardozo e Pereira (2017) analisando áreas atingidas pelo fogo na porção nordeste do Cerrado brasileiro e verificaram proporções maiores na classe de vegetação Savânica.

Para a classe Pastagem foi computado 962 focos de calor e um percentual de 30,52\%. Segundo Oliveira e Jasper (2018) incidências de fogo em pastagens são indícios dos recursos utilizados pelo homem para seu manejo e ampliação. Na Formação Florestal, 336 focos de calor, foram detectados, perfazendo 10,66\% do total registrado na BHRC. 
Revista Tecnologia e Ambiente, v. 28, 2022, Criciúma, Santa Catarina/SC - ISSN Eletrônico 2358-9426 e ISSN Impresso 1413-8131

Já para a Área Urbana e para a classe Outros houve pouca incidência somando 40 focos de calor com $1,27 \%$ percentual.

Os estudos referentes à quantificação de focos de calor incidentes numa faixa (Buffer) de 800 metros das vias no interior da BHRC foram realizados conforme mostra a Figura 7.

As áreas situadas às margens das vias são importantes por contribuir na inicialização da ocorrência do fogo (SILVA, 2020), uma vez que segundo Oliveira et al., (2020) elas estão sujeitas aos incêndios ocasionados pelo fluxo de pessoas e veículos, considerados um dos principais elementos para a ignição de incêndios florestais.

Neste sentido as detecções de focos de calor ocorridos nestas áreas somam um total de 675 nos Buffers das vias e limites urbano-rural o equivalente a 21,40\% do total ocorrido na BHRC, sendo computados valores parciais de 173, 129 e 373, para os anos de 2015, 2017 e 2019, respectivamente.

Entretanto, baixos índices de focos de calor nos buffers aplicados nos limites de transição urbano-rural foram detectados, totalizando 33 e distribuídos nos anos de 2015 , 2017 e 2019 valores iguais a 11, 12 e 10, respectivamente.

Figura 7 - Distribuição de focos de calor nas classes de vegetação e nas margens das rodovias dos anos de 2015, 2017 e 2019.
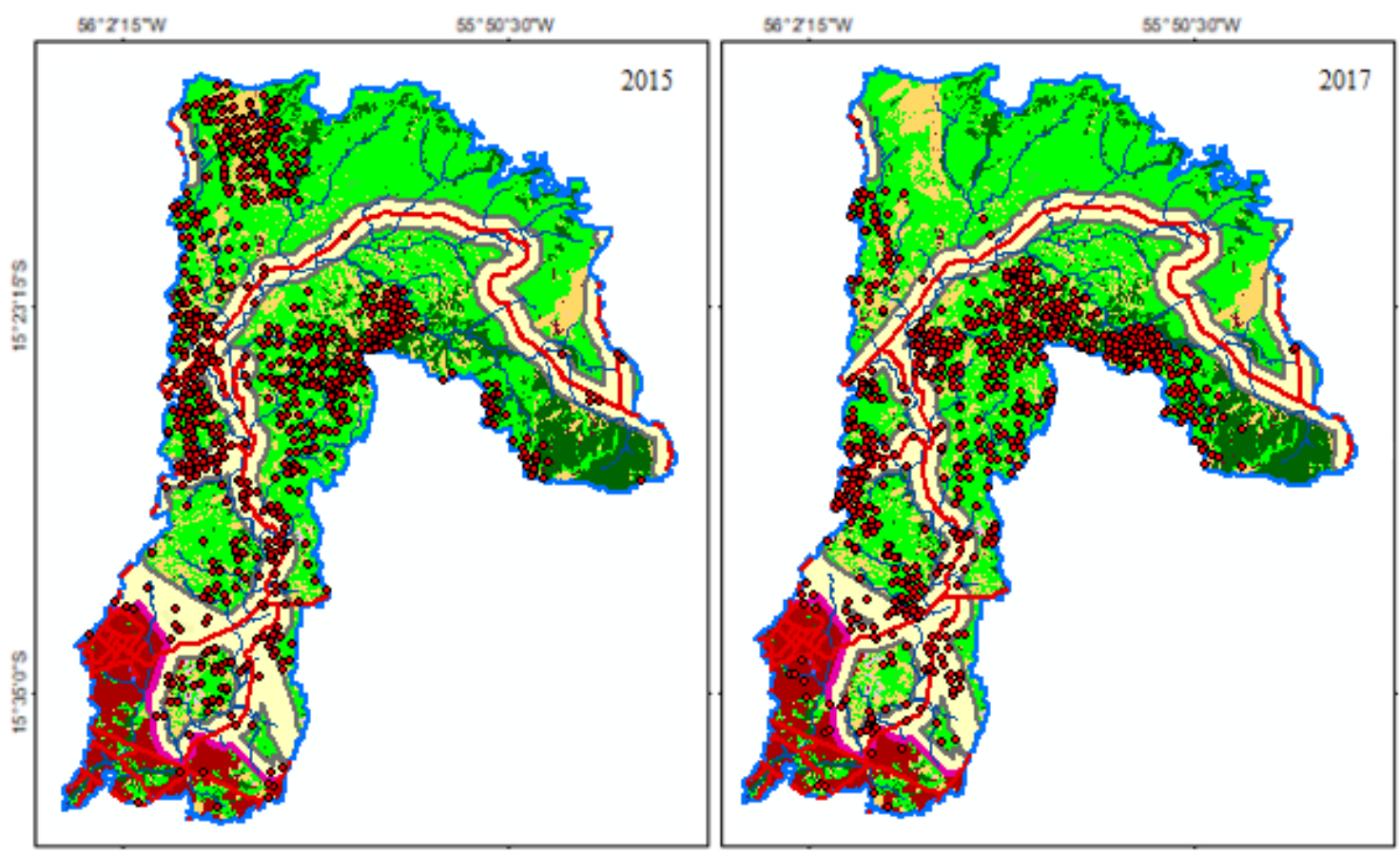

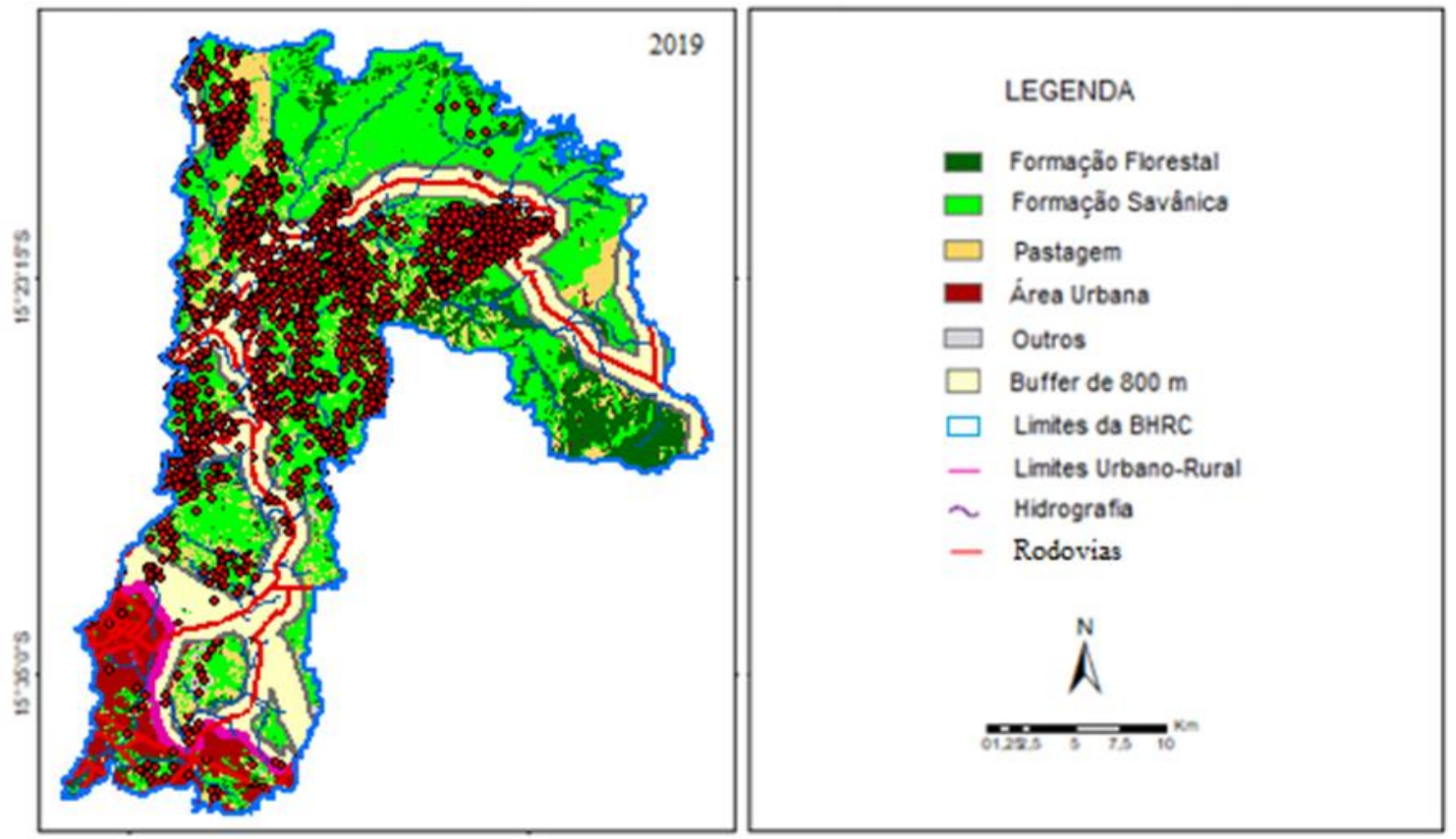

Fonte: Autores (2021)

\section{CONCLUSÃO}

Os resultados mostram que para a série temporal na BHRC a ocorrência de focos de calor na estação seca manteve uma relação inversa com a precipitação pluviométrica.

As classes de vegetação influenciam na distribuição dos focos de calor, visto que a Formação Savânica e Pastagem sofrem maiores incidências por apresentar características que as tornam passíveis ao processo de ignição e propagação do fogo.

O percentual de focos de calor no entorno das vias e áreas urbana é uma informação relevante associado com o padrão de distribuição descrito, indicando locais de maior densidade de incidência e as classes de vegetação mais vulneráveis como elementos de planejamento aos gestores a fim de auxiliar na prevenção e combate ao fogo.

\section{REFERÊNCIAS}

ALBUQUERQUE, E. L. S. Focos de calor na bacia hidrográfica do Rio Poti (ceará/piauí) a partir dos registros do satélite NOAA-18. In: CONGRESSO NACIONAL DE GEOGRAFIA FÍSICA. Anais XVII Simpósio Brasileiro de Geografia Física Aplicada, Campinas -SP, Brasil, 28 de junho a 2 de julho, Unicamp, p. 4708 -4719, 2017. 
ABREU, F. A.; SOUZA, J. S. A. Dinâmica Espaço-temporal de Focos de Calor em Duas Terras Indígenas do Estado de Mato Grosso: uma Abordagem Geoespacial sobre a Dinâmica do Uso do Fogo por Xavantes e Bororos. Revista Floresta e Ambiente, vol. 23, n. 1, p.1-10, 2016.

BOTELHO, M. G. L.; FURTADO, L. G.; LIMA, D. A.; PIMENTEL, B. S.; MACHADO, A. S. O.; JÚNIOR, J. P. Avaliação temporal e espacial de focos de calor em Paragominas. Revista Research, Society and Development. vol. 9, n. 7, p. 2-16, 2020.

COELHO, A. L. N.; GIMENES, A. C. W.; GOULART, A. C. O. Geotecnologias no semiárido mineiro. Revista Agropecuária Científica no Semiárido, vol.15, n.1, p. 56-61, 2020.

COSTA, F. R.; SOUZA, R. F.; SILVA, S. M. P. Análise comparativa de metodologias aplicadas à delimitação da bacia hidrográfica do Rio Doce - RN. Revista Sociedade. \& Natureza, vol. 28, n. 3, p. 429 -442, 2016.

GOMES, D. T.; SAKAMOTO, M. S.; SILVA, A. E. F. Avaliação da Distribuição de Focos de Calor às Margens de Rodovias. Revista Brasileira de Meteorologia. vol. 35, n. 3, p. $467-475,2018$.

INPE-Instituto Nacional de Pesquisas Espaciais. Portal do Monitoramento de Queimadas e Incêndios. Disponível em: http://www.inpe.br/ queimadas. Acesso em: 20 de nov, 2019.

JESUS, J. B.; ROSA, C. N.; BARRETO, I. D. C.; FERNANDES, M. M. Análise da incidência temporal, espacial e de tendência de fogo nos biomas e unidades de conservação do Brasil. Revista Ciência Florestal, vol. 30, n. 1, p. 176-191, 2020.

LEÃO, R. S.; FERREIRA, G. S.; STRAUCH, J. C. M. Análise espaço-temporal dos focos de queimadas e incêndios em Mato Grosso, Brasil, no ano de 2016. Revista Rraega, vol.47, n.1. p.99-119, 2020.

LEMES, G. P.; MATRICARDI, E. A. T.; COSTA, O.; LEAL F, A. Avaliação espaçotemporal dos incêndios florestais no Parque Nacional Serra da Canastra no período de 1991 a 2011. Revista Ambiência, vol.10, n. 1 p. 248 - 266, 2014.

MATOS, N. M.; MATRICARDI, E. A. T.; LEAL, F. A. Modelo probabilístico espacial de áreas queimadas no bioma Pantanal. In: $7^{\circ}$ SIMPÓSIO DE GEOTECNOLOGIAS NO PANTANAL, Jardim, MS, Brasil. Anais Embrapa Informática Agropecuária/INPE, p. 91-100, 2018.

MAZZIERO, F. F. F.; FIORELLI, M. M.; VITTI, D. M. C.; JUNIOR, J. C. T. V. Mapeamento e disponibilização em ambiente web das ocorrências de queimadas urbanas: um estudo de caso no município de Jaú-SP. Revista de gestão e sustentabilidade ambiental, vol. 8, n. p. 344-360, 2019.

MEDEIROS, L. C.; FERREIRA, N. C.; FERREIRA, L. G. Avaliação de modelos digitais de elevação para delimitação automática de bacias hidrográficas. Revista Brasileira de Cartografia, vol. 61, n. 2, p. 137-151, 2009.

MENEZES, E. S.; MUCIDA, D. P.; FRANÇA, L. C. J.; AGUILAR, M. V. M.; SANTOS, A. R.; MORANDI, D. T. Uso de geotecnologias na análise de focos de calor em uma sub-bacia do semiárido mineiro. Revista Agropecuária Científica no Semiárido, vol. 15 , n. 1, p. $57-61,2019$. 
OLIVEIRA, L.A.; JASPER, A. Mapeamento de focos de calor no município de Juara/MT nos anos de 2016 e 2017: construção de banco de dados para análises ambientais regionais. Revista Destaques Acadêmicos, vol. 10, n. 3, p. 230-241, 2018.

OLIVEIRA, M. V. N.; WHITE, B. L. A.; RIBEIRO, G. T. Quantificação do material combustível em fragmento de Mata Atlântica no nordeste brasileiro. Revista Pesquisa Florestal Brasileira, vol. 38, p. 1 - 8, 2018.

OLIVEIRA, U. C.; OLIVEIRA, P. S. Mapas de Kernel como Subsídio à Gestão Ambiental: Análise dos Focos de Calor na Bacia Hidrográfica do Rio Acaraú, Ceará, nos Anos 2010 a 2015. Revista Espaço Aberto, vol. 7, n.1, p. 87-99, 2017.

OLIVEIRA, V. F. R.; SILVA, E. R. S.; SILVA, B. H. M.; VICK, E. P.; LIMA, C. G. R.; BACANI, V. M. Geoprocessamento aplicado ao mapeamento de risco a incêndios. Revista Brasileira de Geografia Física, vol.13, n.03, p. 1194-1212, 2020.

PEREIRA, D. M.; SZLAFSZTEIN, C. F.; ARAÚJO, F. A. Avaliação de risco de desastres na bacia hidrográfica do rio Purus (Brasil) com base em índices compostos. Revista da Associação Nacional de Pós-graduação e Pesquisa em Geografia (Anpege), vol.12 n.17, p.167-190, 2016.

PEREIRA, A. A.; TEIXEIRA, F. R.; LIBONATI, R.; MELCHIORI, E. A.; CARVALHO, L. M. T. Avaliação de índices espectrais para identificação de áreas queimadas no cerrado utilizando dados landsat TM. Revista Brasileira de Cartografia, vol. 68, n.8, p. 1665-1680, 2016.

PRADO, N. V.; COELHO, S. M. S. C. Estudo da Variabilidade Temporal da Profundidade Óptica do Aerossol Utilizando Dados de Sensoriamento Remoto Sobre a Região de Transição entre a Floresta Amazônica e o Cerrado. Revista Brasileira de Meteorologia, vol. 32, n. 4, p. 649-658, 2017.

RESENDE, F. C.; CARDOZO, F. S., PEREIRA, G. Análise Ambiental da Ocorrência das Queimadas na Porção Nordeste do Cerrado. Revista do Departamento de Geografia, vol. 34, p. 31-42, 2017.

RIBEIRO, M., FIGUEIRA, J. E. C. Uma abordagem histórica do fogo no Parque Nacional da Serra do Cipó, Minas Gerais - Brasil. Revista Biodiversidade Brasileira, vol. 1, n. 2, p. 212-227, 2011.

RIBEIRO, T. M.; MENDONÇA, B. A. F.; OLIVEIRA-JUNIOR, J. F.; FERNANDESFILHO, E. I. Fire foci assessment in the Western Amazon (2000-2015). Revista Environment, Development and Sustainability, vol. 23, p. 3-14, 2020.

SANTANA, L. R.; BLANCO, C. J. C.; PESSOA, F. C. L.Ottocodificação de pequenas bacias hidrográficas na Amazônia, REA. Revista de estudos ambientais, vol. 22, n. 1, p.15-23, 2020.

SALES, L. L. N.; SILVA, D. D. S.; LIMA, E. V.; FONSECA, G. T. C.; ALMEIDA, G. S.; RODRIGUES, J. B. 10 municípios maranhenses mais atingidos por focos de queimadas NOAS ANODES de 2014 e 2015. Revista de Geografia, vol. 36, n. 1, p. 5974, 2019.

SILVA, C. V. J.; COSTA, O. B.; MATRICARDI, E. A. T. Detecção de cicatrizes do fogo na vegetação cerrado do distrito federal entre 1999 a 2011. Revista Brasileira de Cartografia, vol. 69, n. 4, p. 687-699, 2017. 
SILVA, R. C. Geoprocessamento aplicado a detecção de risco de incêndios vegetacionais na Bacia Hidrográfica do Rio Dourados. 108p. Dissertação (Mestrado em Geografia) - Universidade Federal de Goiás. Catalão, GO, 2020.

SILVA, C. V. J.; COSTA, O. B.; MATRICARDI, E. A. T. Detecção de cicatrizes do fogo na vegetação cerrado do distrito federal entre 1999 a 2011. Revista Brasileira de Cartografia, vol 4, p. 687-699, 2017.

SOARES, R. V.; BATISTA, A. C.; TETTO, A. F. Incêndios florestais: controle, efeitos e uso do fogo. Curitiba: 2.ed. 2017.

SOUZA, I. M. P. Identificação de áreas queimadas por meio de índices espectrais em regiões do cerrado tocantinense. 59 p. Dissertação (Mestrado em Ciências Florestais e Ambientais) - Universidade Federal do Tocantins, Gurupi, TO, 2017.

STRASSBURG, B. B. N.; BROOKS, T.; BARBIERE. R. F.; IRIBARREM. A.; CROUZELLIS. R.; LOYOLA. R.; LATAWIEC. A. E.; FILHO, F. J. B. O.; SCARAMUZZA, C. A. M.; SCARANO, F. R., FILHO, B. S; BALMFORD, A. Moment of truth for the Cerrado hotspot. Nature Ecology \& Evolution. Vol. 1, n. 99, p. 1, 2017.

TEIXEIRA, N. C. Estudo da dinâmica de queimadas no município de Cuiabá por sensoriamento remoto.2020, 87 p. Dissertação (Mestrado em Ciências Ambientais) Universidade de Cuiabá, Cuiabá, MT, 2020.

WHITE, B. L. A.; WHITE, A. S. Queimadas controladas e incêndios florestais no estado de Sergipe, Brasil, entre 1999 e 2015. Revista Floresta, vol 46, n. 4, p. 561 $570,2015$.

WHITE, B. L. A. Modelos matemáticos de previsão do teor de umidade dos materiais combustíveis florestais finos e mortos. Revista Ciência Florestal, v. 28, n. 1, p. 432-445, 2018 . 